\title{
RESISTENCIA E IDENTIDAD EN LA ISLA DE PROVIDENCIA A TRAVÉS DE LA LITERATURA Y EL CINE
}

\author{
ADRIANA ROSAS CONSUEGRA \\ Universidad del Norte \\ arosas@uninorte.edu.co \\ ORCID: 0000-0002-0874-4763
}

\section{RESUMEN}

En este artículo se señala de qué manera se refleja la resistencia e identidad de la isla de Providencia, en Colombia, a través de la literatura y el cine. Se analiza cómo la decolonialidad es una herramienta para deconstruir los lazos actuales de la colonialidad. Y evidenciar a través del arte, la historia que no nos fue contada, para desmontar la Historia de tonalidad eurocéntrica donde se privilegian a los colonizadores y se menosprecia el origen africano. Para tal fin, se estudia la obra de la escritora Hazel Robinson, el largometraje Keyla de Viviana Gómez Echeverry, el documental de Gloria Triana Bienvenidos a la vieja Providencia, los documentales de la productora Blue Lizard: 15 hitos en Providencia y Providence Today y el de Ana María Jessie Serna, Fishing Her: Mujeres de Sal.

PALABRAS CLAVE: decolonialidad, isla de Providencia, Hazel Robinson, Gloria Triana, literatura de Providencia, cine de Providencia.

\section{RESISTANCE AND IDENTITY ON THE ISLAND OF PROVIDENCE THROUGH LITERATURE AND FILM}

\section{ABSTRACT}

This article outlines how the resistance and identity of the island of Providence, in Colombia, is reflected through literature and film. It discusses how decoloniality is a tool to deconstruct the current bonds of coloniality. And to show through art, the history that was not told to us, to dismantle the History of Eurocentric hue where colonizers are privileged and African origin belittled. To this end, we study the work of the writer Hazel Robinson, the feature film Keyla by Viviana Gómez Echeverry, Gloria Triana's documentary Welcome to Old Providence, the documentaries by the production company Blue Lizard: 15 milestones in Providence and Providence Today, and Ana María Jessie Serna's Fishing Her: Mujeres de Sal.

KEYWORDS: decoloniality, Providence Island, Hazel Robinson, Gloria Triana, Providence Literature, Providence Cinema.

Para abordar la resistencia y la identidad a través de la literatura y el cine, primero analizaremos en qué consiste la decolonialidad, que nos conlleva al estudio de Providencia como isla colonizada con ciertas particularidades. En la postcolonialidad se intenta generar una deconstrucción del sistema colonial y eurocentrista, y se hace especial énfasis que en la interrelación de culturas no 
existe la prevalencia una sobre las otras, sino que se encuentra una equidad donde tienen especial valor todas las culturas que confluyeron en un lugar. En Providencia los indígenas miskitos no habitaron la isla, sino que llegaban a ella para pescar y cazar tortugas. «Los corsarios holandeses habían estado mucho tiempo en el área y cuando los puritanos llegaron a Providencia en diciembre de 1629 a colonizar la isla, encontraron un pequeño grupo viviendo ahí» (Cuming 2015: 53). Los puritanos trajeron esclavos de origen africano de la isla Tortuga y de la costa de Mosquitos, y posteriormente desde Jamaica. Hacia 1635 la isla era una base de corsarios. Después España realizó algunas tomas de la isla y también fue atacada por piratas y bucaneros.

El archipiélago de San Andrés, Providencia y Santa Catalina corrió con una suerte parecida a la de sus hermanas islas del Caribe: pasar por diferentes colonizadores, piratas, filibusteros y corsarios que las habitaron, hicieron suyas, dominaron, y a su vez, trajeron y se llevaron esclavizados de origen africano. Se presentaron las mezclas entre sus diversos habitantes y en una reciente historia en 1802 pasaron a ser parte de la Nueva Granada, sin que Colombia ejerciera una fuerte presencia hasta 1953, fecha en que se creó el Puerto libre, y a partir de ese momento la resistencia y la lucha por una identidad se ha manifestado de diversas maneras, para hacer muros de contención ante una nueva colonialidad: la de los pañamanes, que son los continentales provenientes de Colombia, como los han denominados los raizales; ${ }^{1}$ y también de turcos, como son llamados en Colombia los árabes provenientes del Líbano, Siria y Palestina, principalmente, que llegaron con el fin de crear comercios.

En el continente suramericano en los 90's algunos pensadores latinoamericanos crearon la decolonialidad, con el fin de visibilizar y analizar que lo impuesto por los imperios colonizadores todavía tiene unos lazos hasta el día de hoy, donde se privilegia lo que ellos dejaron y se menosprecia las otras culturas que hicieron parte de las mezclas.

El creole ${ }^{2}$ es la lengua de Providencia y es la herramienta más grande que tiene en estos momentos como resistencia ante la influencia y gobierno de

1 Raizal son las personas nativas del archipiélago de San Andrés, Providencia y Santa Catalina, afrodescendientes, con tradiciones propias y el creole como lengua, resultado del mestizaje de culturas, entre ellas: la africana, la de colonos ingleses, españoles y holandeses, principalmente, y de las Antillas. «La comunidad raizal es reconocida como tal desde la promulgación de la constitución actual que nos rige, adquiriendo el estatus de grupo étnico. Esta comunidad que vive en las islas de San Andrés, Providencia y Santa Catalina y cuyo origen se remonta a los siglos XVII y XVIII, ha sido desplazada poco a poco por el proceso que se conoce con el nombre de "colombianización" desde inicios del siglo XX, especialmente desde 1953 cuando el dictador Gustavo Rojas Pinilla declara el puerto libre, recrudeciendo la marginación política y cultural de los raizales por parte de los continentales (los paña) (Guevara, 2007)» (Castaño 2017: 239).

2 Es una lengua originaria del inglés y de lenguas africanas, sobre todo, las lenguas kwa, mende y mandinka. 
Colombia. Con el creole «se elimina la falsa universalidad, el monolingüismo, la pureza. Lo diverso es la armonía, es el origen de sus potencialidades, con una consecuencia, ‘la necesidad de aceptarnos complejos» (Rosas 2019: 36).

En los colegios el idioma que se utiliza para impartir las clases es el español, se da una materia en inglés, y el creole nunca se maneja dentro de las aulas de manera académica. Sin embargo, en las casas y en las calles el creole es la lengua para la comunicación. El cantante de Providencia Elkin Robinson en su canción Creole vibration (2017) nos habla de lo que ocurre en los colegios donde no se puede hablar en creole, sino solamente en los recreos: «I need my creole vibration/ cause is a full vibration/ is an ancestral vibration/ take me back to my roots/ [...] We need our language/ We need our culture in a creole vibration». El creole conlleva identidad, es regresar a lo ancestral, a las raíces.

Frantz Fanon el teórico martiniqués en su libro Piel negra, máscaras blancas (1952) explica la importancia del creole a partir de su crítica:

El problema que nos planteamos... es el siguiente: el negro antillano será más blanco, es decir, se aproximará más al verdadero hombre, cuanto más suya haga la lengua francesa. No ignoramos que esta es una de las actitudes del hombre frente al Ser. Un hombre que posee el lenguaje posee por consecuencia el mundo que expresa e implica ese lenguaje. Se ve a dónde queremos llegar. En la posesión del lenguaje hay una potencia extraordinaria. (Fanon 2009: 49)

En nuestro caso, el español es al francés, y se quiere imponer una cultura que tiene como principal motor el idioma, entonces, la principal herramienta para hacerle frente es el creole.

Fanon aclara que al referirse al hombre antillano está hablando de 'todo hombre colonizado'. Y Providencia tuvo su historia de isla colonizada por potencias europeas, estuvo un tiempo sin casi influencia de Colombia, hasta 1912 cuando fue creada la Intendencia Nacional de San Andrés y Providencia comenzó. El tiempo de 'libertad' sin una presencia fuerte de gobernación de Colombia sobre las islas, en 1902, lo manifiesta la escritora Hazel Robinson en la presentación de su novela El príncipe de St. Katherine: «La presencia del Estado colombiano se limitaba a la bandera izada en las instalaciones gubernamentales» (2009: 9).

Desde 1953 son fuertes las injerencias de Colombia, y en la actualidad está siendo colonizada por Colombia, y se han generado una serie de transformaciones como:

todo pueblo colonizado, es decir, todo pueblo en cuyo seno ha nacido un complejo de inferioridad debido al entierro de la originalidad cultural local, se posiciona frente al lenguaje de la nación civilizadora...Será más blanco en la medida en que hay rechazado su negrura, su sabana. (Fanon 2009: 50)

Puntos que se ven ejemplificados en el rechazar su forma de construcción tradicional de casas de madera, el cultivar y comer de su producción agrícola, 
considerar que la mayoría de las cosas que vienen de afuera son mejores que las propias, no utilizar el sistema tradicional de transporte que era el caballo o caminar y generalizar el uso de las motos, el preferir parejas que no sean de la isla, el cambio de las tradiciones alimentarias y el actual sedentarismo ha conllevado a que se disparen enfermedades como la diabetes, olvidar las músicas tradicionales de origen antillano, el uso de las plantas, prácticas religiosas y narraciones orales de origen africano, etc.

Walter Mignolo, uno de los teóricos de la decolonialidad, afirma que lo descolonial es deconstruir, desarmar o deshacer lo colonial (2018). En Providencia es evidenciar a través del arte, la historia que no nos fue contada, y desmontar la Historia donde los ingleses puritanos fueron unos religiosos ejemplares que llegaron a la isla, trataban muy bien a los esclavizados y hasta llegaban a casarse con negras. La historia por relatar es la que nos cuenta Hazel Robinson sobre la esclavitud, sin llegar a mostrar realidades tan duras como las que nos relata la guadalupeña Maryse Condé en su libro Yo, Tituba, la bruja negra de Salem, quien muestra las denigraciones que realizan los colonos a los esclavizados, la deshumanización, el desprecio y todos los castigos impartidos. Una novela así cambia la percepción de la colonización inglesa por parte de los puritanos y su relación con los descendientes del África que fueron traídos a la fuerza al Caribe. Ejemplo de ello es el siguiente apartado de la novela:

Media docena de mujeres iguales a ella, con la piel de color leche agria, los cabellos estirados hacia atrás... Me observaron espantadas con sus ojos multicolores... Lo que me asombraba y me indignaba no eran tanto sus opiniones como la manera de expresarlas... Hablaban de mí, pero al mismo tiempo me ignoraban. Me tachaban del mapa de los humanos... No existía... Era atroz. Tituba se tornaba fea, grosera, inferior, porque ellas así lo habían decidido... Ellos no habían elegido sus cadenas. No se habían encaminado por su propia voluntad hacia el mar suntuoso y embravecido para librarse a los traficantes y ofrecer sus espaldas al hierro del marcaje. (Condé 1986: 89-92)

Para estas mujeres colonas puritanas inglesas, Tituba no existe. Los más de dos siglos que duró la esclavitud en el Caribe sirvió para profundizar el sentimiento de inferioridad como un carbón encendido dentro de la piel, que carcome y nunca se apaga. El ninguneo del colonizador hacia lo indígena que encontraron y luego hacia los esclavizados traídos del África tiene unas repercusiones que todavía tocan las fibras de los habitantes del planeta, es lo que denomina Walter Mignolo las clasificaciones del europeo para justificar sus atrocidades y sus deseos capitalistas que tan bien profundiza Antonio Benitez Rojo en su texto La isla que se repite. Para Mignolo, «la devaluación jerárquica de poblaciones no-europeas concurrieron con la legitimación Europea de invadir, expropiar, explotar y... legitimar los procedimientos económicamente invasivos» (2008: 7).

En el archipiélago, para hacer frente y resistencia frente a la Historia, con manifestaciones de decolonialidad en la escritura de novelas, encontramos a la sanandresana Hazel Robinson Abrahams, de familia paterna de Providencia, 
quien ha vivido algunos años en esta isla, y de sus cuatro novelas, las tres últimas se desarrollan en Providencia y Santa Catalina: No give up, man! (2002), Sail ahoy!!! Vela a la vista (2004), El príncipe de St. Katherine (2009) y Si je puis I will, if I can (2019), publicadas por la Universidad de Colombia, Sede Caribe.

La recuperación de la memoria oral es una forma de resistencia manifiesta en la escritura de Hazel Robinson. Sus novelas se desarrollan en la época de la esclavitud, en la de finales del siglo XIX hasta mediados del XX en que el mar Caribe era recorrido por goletas, en tiempos en que las parteras viajaban entre San Andrés y Providencia para atender a mujeres con sus saberes ancestrales (ya no existen parteras en el archipiélago, un saber ancestral que se perdió), el tiempo en que estaban alejados del resto del Caribe, y Providencia era un lugar propicio para el anonimato de ciertas personas que llegaban provenientes de otros países.

Sus narraciones nos trasladan a sus costumbres y formas de vida ancestrales, que gozan de una gran potencia para conocer los orígenes y el pasado de los que hoy pueblan sus islas, y cumplen la función de lo que Robinson nos explicita en la presentación de su libro Sail Ahoy!!! ;Vela a la vista!: «La historia se supone debe darnos sentido de identidad, un sentimiento de quienes éramos, la distancia que hemos recorrido y debe tomarse como plataforma de desembarque al futuro» (2004: 9). Una resistencia asociada a la formación de una identidad. Una identidad a partir de la resistencia.

En cine se han realizado solo dos largometrajes en Providencia: Keyla y El día de la cabra, sus directores son Viviana Gómez Echeverry, caleña, y Samir Oliveros, bogotano, respectivamente. Los dos son muy recientes, del 2017. Y El día de la cabra no es un filme para analizar desde la perspectiva de resistencia e identidad.

En Keyla se muestran algunos actos representativos de la actualidad providenciana con elementos que pueden remitirnos a un sentido de resistencia y muestran algunos elementos de la vida contemporánea de la isla, como son: El buscar (gustar, preferir) parejas que vienen de la 'metropoli' (como denomina Fanon a las ciudades fuera de la isla), es algo que refleja Keyla en dos instancias: la mujer del padre de Keyla es española y el novio de Keyla cuando ve turistas va tras de ellas. El punto de quiebre es cuando Keyla decide terminar con este novio y genera una reflexión a un gusto colonial que perdura hasta nuestros días por preferir lo extranjero aún estado con alguien isleño. Este gusto por las mujeres foráneas que se nota en Providencia tiene que ver con:

un fenómeno psicológico que consiste en creer en una apertura del mundo en la medida en la que se rompen las fronteras. El negro, prisionero en su isla, perdido en una atmósfera sin la menor salida, experimenta como una bocanada de aire esa llamada de Europa. (Fanon 2009: 52)

La Europa de la que habla Fanon en Providencia se convierte en lo continental (como se llama a Colombia) y todo lo que venga de fuera de 
Colombia, porque es un regreso a la antigua colonia inglesa que alguna vez fueron.

Debido al sentimiento de inferioridad de todo colonizado, como ya lo señalaba Fanon, tiene otra cara al querer ser como el europeo, como el continental, y él lo denomina como intento por «alcanzar un sentimiento de igualdad con el europeo y su modo de existencia» (2009: 54). Por ese motivo se tiende a imitar lo que venga de fuera y tratar de abolir lo que identifique al pueblo raizal, para tratar de igualarse con los de la metrópoli.

Hay ciertas costumbres ancestrales que se muestran en el film, pero que no tienen una trascendencia en cuanto a resistencia: los fríjoles que se desgranan para hacer un arroz tradicional con coco, los bailes o competencias en las fiestas de mitad de año (pero que no son continuas durante los otros meses), la pesca, la pérdida de los hombres en ultramar...

En Providencia se han realizado una serie de documentales que muestran las costumbres ancestrales, pero al querer particularizarlas en la isla, ocurre una mayor reacción, porque los isleños no ven qué tienen en común con el resto de Colombia, sino que por lo contrario la diferencia se resalta. ¿Entonces, qué hacer? ¿Cómo salir de la alienación?

La primera persona que realizó un audiovisual en Providencia que tuvo una difusión nacional fue Gloria Triana, a través de su programa Yuruparí. Triana dirigió con Jorge Ruiz Ardila Bienvenidos a la vieja Providencia en 1984. Es un documental valioso ya que almacenó costumbres ancestrales antes de que asfaltaran la carretera, ya que este cambio hizo que la mayoría de las personas que vivían en las montañas bajaran a las zonas costeras cerca de la carretera, especialmente porque comenzaron a contar con servicio de acueducto y energía eléctrica que no tenían arriba. Este traslado masivo hizo que se destruyeran o se fueran perdiendo varias costumbres, como es el trasladarse de un lugar a otro en caballo, que en la novela Sail Ahoy!!! se muestra al recorrer el camino entre Lazy Hill y Old Town en caballo. Triana también muestra los trapiches para hacer panela y elaborar el Bush Rum (ron artesanal). Este documental viene a convertirse en un material histórico para reconstruir la isla en las fiestas de julio hace 45 años.

En la actualidad la productora Blue Lizard ha realizado varios documentales, como: 15 hitos en Providencia (2019) y Providence today (2015), entre otros. Providence today es el documental de Blue Lizard que aporta más a cómo perduran en la Providencia de hoy algunos elementos de identidad que vienen del pasado o que reivindican una identidad actual, como son: el no cortar árboles en un arroyo para cuidar el agua, que el himno nacional de Colombia sea cantado en inglés y no en español, la competencia de caballos y botes, las danzas tradicionales, la pesca, el daño que ocasionó la creación del Puerto Libre en 1953, los 17 megaproyectos que han tumbado para preservar a la isla de grandes compañías turísticas, que dañarían su sostenibilidad y su independencia territorial como pueblo raizal de origen africano, ciertas 
tradiciones como el anuncio de los funerales, y el problema del tráfico de drogas que lleva a que varios isleños estén en las cárceles en Tampa por llevar cargamentos en las lanchas rápidas hacia el norte. En torno a la decolonialidad una mujer explicita que los apellidos actuales se deben a que los colonos daban sus apellidos a sus esclavizados, sin embargo, no se menciona sobre el trato que ellos les daban, o las condiciones en que los tenían. Feliciano Whitaker, uno de los entrevistados, es el único que dice que se debe «regresar a los ancestros y a los africanos».

En 15 hitos en Providencia es una animación que muestra la historia de Providencia desde 1631 hasta el fallo de La Haya en 2012. Es un recorrido detallado en las fechas y eventos importantes para la isla, sin embargo, no es un audiovisual que proponga una relectura de la historia, o que nos muestre una versión diferente a la de la esclavitud como nos la ha enseñado la Historia, o que la visión de los colonizadores sea transgredida.

La sanandresana Ana María Jessie Serna realizó un documental sobre pescadoras en San Andrés, Providencia y Santa Catalina, titulado Fishing Her: Mujeres de Sal (2018), la investigación fue auspiciada por la Universidad Nacional, Sede Caribe, y la directora de la investigación fue Adriana Santos Martínez. El propósito del audiovisual es recuperar la memoria colectiva del trabajo de mujeres pescadoras, muchas veces no reconocido en sus comunidades. Este oficio hace parte de las labores ancestrales del archipiélago, ya que el mar es un territorio muy importante para el pueblo raizal, al devenir gran parte de su sustento y alimentación del océano, y también al ser una labor tradicional efectuada por generaciones.

La importancia del documental radica en que está centrado en mujeres y es realizado por una raizal, puntos diferenciales con respecto a los otros audiovisuales analizados. Fishing her: Mujeres de Sal se enfoca en la pesca, un oficio que por tradición era realizado principalmente por hombres, y se muestra solo a mujeres pescadoras, más de la mitad son de Providencia y Santa Catalina. También, sirve para reivindicar que este oficio siga siendo realizado por la generación de jóvenes, y muestra cómo las mujeres pueden ser independientes económicamente de los hombres y son felices al estar en el mar, como lo afirman, Jesusita Hoy Arias, una de las pescadoras: «Desde que era una niña, he estado siempre en el mar. Mi padre fue pescador, y ahora soy una pescadora, también»; y la joven pescadora de Old Town, en Providencia, Carrie May: «Nosotros tenemos que aprender a proteger y explorar el mar». Esta labor continua en las jóvenes, y no solo para temporadas especiales, como los carnavales, sino en el día a día, y como un trabajo y realización personal.

Este documental de Jessie Serna lo podemos relacionarlo en cierta manera con las reflexiones que hace el director de cine Ciro Guerra, sobre la realización de su film El abrazo de la serpiente (2015), que se desarrolla en el Amazonas colombiano con tribus indígenas: 
No es una cuestión de folclor o de culturas que están muertas, sino un conocimiento que tiene que ver con lo que el hombre está buscando hoy en día, que es cómo lograr un equilibrio con la naturaleza, con los recursos que se tienen sin devastarlos y procurando la armonía no solo entre el hombre y la naturaleza sino entre las diferentes comunidades que componen la humanidad. Y cómo ese lograr un equilibrio y una armonía es una manera de alcanzar una felicidad que no es posible con los sistemas políticos y sociales actuales. (Abrazo de la serpiente - Entrevista con Ciro Guerra 2015: 1)

Porque el documental Fishing her: Mujeres de sal, es el despliegue de una cultura ancestral viva, la pesca artesanal, que va en armonía con la naturaleza, contraria a la pesca industrial que arrasa con los fondos marinos, y a la que le importa solo el ahora sin tener en cuenta el futuro y la sostenibilidad de los seres que habitan el mar. La armonía de la que habla Ciro Guerra, es similar a la que buscan los integrantes de la Veeduría Cívica Old Providence, quienes defienden los derechos étnicos de su pueblo raizal. Ellos proclaman y luchan para que los proyectos turísticos foráneos no lleguen a Providencia y Santa Catalina, porque afectarían la conservación ecológica y de su cultura. En general, buscan que el pueblo raizal de estas islas no sea desplazado físicamente de su territorio, ni en el sentido económico, como ha ocurrido con San Andrés. ${ }^{3}$

A manera de conclusiones, podríamos afirmar que en cine está por crearse un largometraje realizado por raizales que refleje un acercamiento diferente a la Historia, punto que sí ha realizado Robinson en sus novelas. Hasta el momento, tanto en ficción como en documentales se han realizado acercamientos a las tradiciones, pero ninguno ha apuntado a un desmantelamiento de la colonialidad, tal como lo plantea Walter Mignolo al generar:

un proceso de descolonización del conocimiento y de la formación de subjetividades que mantiene, legitima y naturaliza la colonialidad del poder mundial. 'Desprenderse' no significa retirarse a la selva o a la montaña para vivir como ermitaños sino que significa desprenderse de las reglas del juego y comenzar a jugar otro juego. (Mignolo 2008: 19)

Está por impartirse de manera regular la etnoeducación en los colegios para transmitir los saberes de las personas mayores a los niños y adolescentes, para una recuperación y valoración de los saberes ancestrales provenientes del

\footnotetext{
${ }^{3}$ La siguiente frase de Josefina Huffington, presidenta de la Veeduría Cívica Old Town, resume lo que buscan para la isla: «En relación con la estabilidad ecológica del ecosistema, la Veeduría Cívica Old Providence se opuso a la ampliación de la pista del aeropuerto, en tanto se afectaba gravemente el área de conservación conocida como McBean Lagoon, área donde se sustenta nuestra soberanía alimentaria, además de proyectar el incremento de una demanda turística que no consultaba la capacidad de carga técnica de las islas de Providencia y Santa Catalina, sumado a que aun en la actualidad, no tenemos hospital, agua potable, ni alcantarillado, lo que en ultimas ocasiona además, la contaminación de nuestra área marítima» (Veeduría rechaza 'denuncias sin rostro' en Providencia 2019).
} 
África, y no solo de Europa, lo que conducirá a valoración de lo propio frente a lo que viene de afuera.

También se sugiere la realización de más audiovisuales que sean transmitidos por la canal de televisión Teleisla en horarios de amplia recepción, con las propuestas de la decolonialidad, así como se ha hecho con las historias de Anansi. ${ }^{4}$ En Providencia en el libro Historias de Anansi de la vieja Providencia ${ }^{5}$ se trasladaron dos historias de Anansi (una araña quien siempre se sale con las suyas) y tres historias más, entre ellas Bolingo. Lo particular del libro es que son historias narradas en creole por Hildreth Bent Eden, Delia Eden McLean y Dionicia Gómez Davis y posteriormente traducidas al español e inglés por Marcia L. Dittmann, publicadas por el Banco de la República.

Para próximos audiovisuales se sugiere profundizar en la frase de Feliciano Whitaker de «Regresar a los ancestros y a los africanos», porque es notorio el mostrar las tradiciones que siguen hasta nuestros días para realzarlas y darles su importancia, pero también, mediante el arte ayudar a desmontar el pensamiento eurocéntrico y racista, y plantear la decolonialidad del poder, que para Aníbal Quijano es:

entendida como patrones de poder establecidos en la colonia, pero que aún hoy en día perduran, basados una jerarquía racial y en la formación y distribución de identidades sociales (blancos, mestizos, etc.), que borran las diferencias históricas, culturales y lingüísticas de los pueblos indígenas y los de origen africano y las convierten en las identidades comunes y negativas de 'indios' y 'negros'. (Walsh 2005: 42)

De esta manera, la identidad del pueblo providenciano alcanza una equidad de todas las culturas que la integran, brindando la importancia a la africana en la isla, como es el conocimiento de las plantas, origen de las comidas, los cultos religiosos, las trenzas utilizadas en el cabello, la veneración e importancia de las ceibas, la comunicación con la naturaleza, con los invisibles... Y sobre todo, el conocer las condiciones en que vivían en las islas, cuál era la relación con los colonizadores, cómo eran sus comportamientos, cómo los trataban y cómo los deshumanizaban, para no seguir venerándolos, por el desconocimiento de esa historia, por los gritos y lamentos de los esclavizados de los que habla Hazel Robinson en su libro No give up, maan!, «se

\footnotetext{
${ }^{4}$ Marcia L. Dittmann explica que «las historias de Anansi se encuentran extendidas por el Caribe anglófono e incluyen toda una gama de cuentos afro-anglo-caribeños. Sin embargo, gran parte de estas historias tienen como protagonista a la araña Anansi, de la tradición cultural ashanti y de otras culturas de África Occidenal» (Bent-Eden et al. 2016: 5).

${ }^{5}$ Sin embargo, algunos providencianos consideran que las historias de Anansi «son más de San Andrés» y no las consideran como propias. Una de las autoras afirma que estos cuentos provienen de Jamaica, ya que muchos esclavos que llegaron a Providencia provenían de esa isla. Pero tampoco es generalizado que su origen es africano, lo que viene a reafirmar la teoría de que muchas de las tradiciones provenientes de esclavizados no tienen la apreciación adecuada a una equidad intercultural por la que aboga la decolonialidad.
} 
convirtió ese día en el calabozo de la nave donde todos habían iniciado este obligado cautiverio y el disfraz de sus gritos, carcajadas y cantos se convirtió pronto en suspiros y después en inconsolables llantos» (2002: 18); por las marcas con hierros candentes en sus pieles, «por las marcas que llevaba en el brazo izquierdo pertenecía a las plantaciones del suroeste» (2002: 35); por las violaciones a las esclavizadas: «aumentaba en esta forma en cinco por año los esclavos de la plantación. No los reconocía como sus hijos, pero le complacía saber que aumentaban los brazos en el campo» (2002: 39); por la utilización de sus cuerpos «después dio la orden de que sea acostaran, y caminando por encima de ellos, llegó hasta donde estaba la abertura» (2002: 38).

Y así como expresan Jean Bernabé, Patrick Chamoiseau y Raphäel Confiant, en su libro Elogio a Creolidad, sobre el papel del arte, y en este caso, el cine y la literatura, como canales para difundir la creolidad, para reflexionarla, para pensarla, como un paso previo para 'la consolidación de nuestra identidad' (Bernabé et al. 2011: 25). ${ }^{6}$

Para finalizar, bien podríamos utilizar el título de la segunda novela de Hazel Robinson, como símbolo de resistencia y de formación de identidad para Providencia ante el futuro que viene para esta isla y sus habitantes, como la misma escritora lo explica en la presentación de su libro Sail Ahoy!!! ¡Vela a la vista!:

"No give up, maan!" (¡No te rindas, hombre!) a veces un saludo y otras una amonestación, una advertencia, o un consejo que intercambiaban los esclavos de las islas y luego sus descendientes, logró que la comunidad no se rindiera ante los ultrajes de la esclavitud ni frente a un futuro desconocido. (2004: 9)

\section{BIBLIOGRAFÍA}

BENÍTEZ Rojo, A. (1986), «La isla que se repite: para una reinterpretación de la cultura caribeña», Cuadernos hispanoamericanos, 429, marzo, 115-132.

Bent Eden, H., Eden McLean, D. y Gómez Davis, D. (2016), Historias de Anansi de la Vieja, Providencia, Bogotá, Banco de la República.

Bernabé, J., Chamoiseau, P. y CONFIANT, R. (2011), Elogio de la creolidad, Bogotá, Editorial Pontificia Universidad Javeriana.

CONDÉ, M. (1986), Yo, Tituba, la bruja negra de Salem [libro electrónico], Bajaebooks.com. Disponible en: <https://bajaebooks2.net/books/search/yo\%20tituba/>.

CuMING, S. (2015), A short history of Providence and San Andres (1629-1901). Breve historia de Providencia y San Andrés (1629-1901), Colombia, Eecutivos gráficos.

Dominguez, G. (dir.) (2019), 15 hitos en Providencia, Providencia, Prod. Blue Lizard.

Dominguez, G. (2015), Providence today, Providencia, Prod. Blue Lizard.

Fanon, F. (2009), Piel negra, máscaras blancas, Madrid, Ediciones Akal.

\footnotetext{
${ }^{6}$ Tomado de Rosas Consuegra, Adriana. En: Derek Walcott y Hazel Robinson en el mar de lo afrocaribe (2019, p. 36)
} 
Gómez ECHEVERrY, V. (dir.), Keyla, Bogotá, Cineplex.

GUERRA, C. (dir.), El abrazo de la serpiente, Bogotá, Cinecolor films.

MigNOLO, W. D. (2008), «La opción descolonial», Letral, 1, 4-22.

Oliveros, S. (dir.) (2017), El día de la cabra, Bogotá, Laboratorios Black Velvet.

ReISE-NACH-KOLOMBIEN. Abrazo de la serpiente - Entrevista con Ciro Guerra [en línea]. München: Reise-nach-Kolombien.de, 27 de mayo de 2018 [Consulta: 23 de septiembre de 2019]. Disponible en: <https://www.reise-nachkolumbien.de/abrazo-de-la-serpiente-entrevista-ciro-guerra/>.

ROBINSON ABRAHAMS, H. (2002), No Give Up, Maan! Bogotá, Editorial UnibiblosUniversidad Nacional de Colombia.

ROBINSON ABRAHAMS, H. (2004), Sail Ahoy!!! ¡Vela a la vista!, Bogotá, Editorial Unibiblos-Universidad Nacional de Colombia.

ROBINSON ABRAHAMS, H. (2009), El príncipe de St. Katherine, Bogotá, Editorial Unibiblos-Universidad Nacional de Colombia.

ROBINSON ABRAHAMS, H. (inédito), Los 5 delantales de mi abuela, manuscrito facilitado por la autora.

ROBINSON, E. Creole vibration [en línea]. Llorona records, 2017 [Consulta: 1 de octubre 2019]. Disponible en: <https://lloronarecords.bandcamp.com/album/come-roundelkin-robinson>.

RosAs CONSUEGRA, A. (2019), «Derek Walcott y Hazel Robinson en el mar de lo afrocaribe», en Apropiación cultural Caribe, Barranquilla, Editorial Universidad Simón Bolívar, 20-40.

TrianA, G., Bienvenido a la vieja Providencia [documental en línea]. Isla Providencia, 1984 [Consulta: 1 de octubre de 2019]. Disponible en: $<$ http://www.proimagenescolombia.com/secciones/cine_colombiano/peliculas_co lombianas/pelicula_plantilla.php?id_pelicula=1627\&lang=en>.

WALSH, C. (2005), «Interculturalidad, conocimientos y decolonialidad», Signo y Pensamiento, vol. XXIV(46), enero-junio 2005, 39-50.

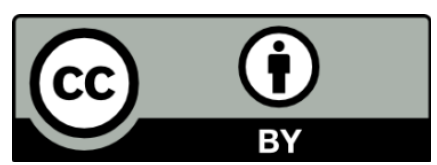

Los textos publicados en esta revista están sujetos - si no se indica lo contrario - a una licencia de Reconocimiento 3.0 España de Creative Commons. Puede compartirlos con terceros siempre que reconozca su autoría, la publicación inicial en esta revista y las condiciones de la licencia. 